\title{
Fontan Operasyonu Sonrası Şilotoraks Gelişen Olguda Oktreotidin Etkinliği
}

\author{
EFFICACY OF OCTREOTIDE IN CASE WITH CHYLOTHORAX OCCURRING AFTER FONTAN \\ OPERATION
}

\author{
Savaş DEMIRPENÇE ${ }^{1}$, Seda TUNCA ${ }^{2}$, Barış GÜVEN ${ }^{4}$, Emin Alp ALAYUNT $^{3}$, Vedide TAVLI ${ }^{5}$
}

${ }^{1}$ Buca Kadın Doğum ve Çocuk Hastalıkları Hastanesi, Çocuk Kardiyoloji Bölümü

2Şifa Üniversitesi, Çocuk Sağı̆̆ı ve Hastalıkları Anabilim Dalı

3Sifa Üniversitesi, Çocuk Kalp-Damar Cerrahisi

${ }^{4}$ Tepecik Eğitim ve Araştırma Hastanesi, Çocuk Kardiyoloji Bölümü

${ }^{5}$ Şifa Üniversitesi, Çocuk Sağı̆ğı ve Hastalıkları Anabilim Dalı Çocuk Kardiyoloji Bilim Dalı

\author{
Savaş DEMIRPENÇE \\ Buca Kadın Doğum \\ ve Çocuk Hastalıkları Hastanesi \\ Çocuk Kardiyoloji Bölümü \\ Ahmet Yesevi Cad \\ 35390, Buca / IZMIR \\ Tel: (232) 4540101-251 \\ Faks: (232) 4540102 \\ e-posta: \\ savasdemirpence@yahoo.com
}

\begin{abstract}
ÖZ
Postoperatif şilotoraks, sıklıkla doğumsal kalp hastalıklarının cerrahisi sonrası görülür. Şilotoraks, özellikle tek ventrikül fizyolojisi olan çocuklarda uzamış hastane yatışı, morbidite ve mortalitenin önemli nedenlerinden biridir. Ductus thoracicus ve aksesuvar lenf kanallarının hasarlanması dışında, sistemik venöz basıncın torasik duktus basıncını aştığı Fontan operasyonu şilotoraksa neden olabilir. Diyet modifikasyonlu konservatif tedavi ile oktreotid postoperatif şilotoraksın standart tedavi yöntemi olarak kabul edilmiştir. Biz bu yazıda Fontan girişimi sonrası gelişen ve oktreotid ile başarılı şekilde tedavi edilen bir şilotoraks olgusunu sunduk. Sonuç; özellikle kavapulmoner anastomoz sonrası plevral effüzyon gelişen çocuklarda şilotoraks akla gelmelidir ve cerrahi girişim gereksinimini azaltmak için konservatif tedaviye ek olarak oktreotid eklenmelidir.

Anahtar sözcükler: Çocuk, Fontan operasyonu, şilotoraks, oktreotid

ABSTRACT

Postoperative chylothorax commonly occurs following surgical repair of congenital heart disease. Chylothorax is one of the main reasons of lengthened hospitalization, morbidity and mortality amongst particularly children with single ventricle physiology. Apart from laceration of ductus thoracicus and accessory lymphatics, Fontan procedure in which systemic venous pressure exceeds thoracic ductus pressure may lead to chylothorax. Conservative therapy with diet modification and octreotide has been accepted as standard therapy of postoperative chylothorax. Here, we report a case of chylothorax arising secondary to Fontan procedure, and treated curatively with octreotide. Conclusion; chylothorax must be considered, especially in children with pleural effusion occurring after cavapulmonary anastamosis, and the octreotide should be added to conservative therapy to reduce the necessity for surgical management of chylothorax.
\end{abstract}

Keywords: Child, Fontan operation, chylothorax, octreotide 
Şilotoraks çocuklarda konjenital veya edinsel nedenlere bağlı gelişebilen nisbeten nadir görülen patolojik bir durumdur. Postoperatif şilotoraks sıklıkla konjenital kalp hastalığ1 cerrahisinden sonra yoğun bakım ünitesindeki hastalarda görülmektedir (1). Konjenital kalp hastalıklarında cerrahi düzeltme ameliyatı sonrası postoperatif şilotoraks insidansı \%2 olarak bildirilmekle birlikte bu oran bazı hasta gruplarında \%5'e kadar çıkmaktadır (2). Şilotoraks tanısında plevral veya perikardiyal sıvının üç karakteristik özelliğinden en az birisinin varlığı gereklidir. Bunlar; 1) süt görünümü; 2) sıvı trigliserid düzeyinin 110mg/dL üzerinde oluşu; 3) sıvı hücre içeriğinin 1000 hücre/mL üzerinde ve lenfosit hakimiyetinde ( $\%$ \%0) oluşu ile birlikte steril kültür varlığıdır (3). Şilotoraks özellikle tek ventrikül fizyolojisi olan hastalarda mortalite ve hastanede yatış süresini artıran başlıca morbidite nedenlerinden birisidir (4). Son yıllarda postoperatif şilotoraksın tedavisinde somatostatinle tedavi seçeneği yeni bir tedavi modalitesi olarak konservatif tedaviye eklenmiştir (5).

Fontan prosedürü; triküspid atrezisi, mitral atrezi ve tek ventrikül fizyolojisi gibi anatomik düzeltmenin tam mümkün olmadığı bazı kompleks konjenital kalp hastalıklarında fizyolojik düzeltme sağlamaktadır. Duktus torasikus veya aksesuvar lenfatiklerin hasarı veya sistemik venöz basıncın torasik duktus basıncından daha yüksek olduğu Fontan operasyonlarından sonra izlemde şilotoraks gelişebilmektedir (6). Bu yazıda, Fontan operasyonu sonrası şilotoraks gelişen ve konservatif tedaviye ilave olarak oktreotid kullanımı ile kısa sürede sıvı drenajında çok belirgin azalma elde edilen bir olguyu, çocuklarda Fontan sonrası şilotoraksın medikal tedavisinde oktreotid kullanımının etkinliğini vurgulamak amaçlanmıştır.

\section{OLGU}

Dekstrokardi, pulmoner atrezi, triküspit atrezisi, ventriküler septal defekt ve tek ventrikül fizyolojisi tanılarıyla izlenen ve bir ay önce Fontan operasyonu yapılan 6 yaşındaki erkek olgu ateş, öksürük, halsizlik, kusma ve karın ağrısı yakınmaları ile başvurdu. Öyküsünden yenidoğan döneminde sol Blalock-Taussig (BT) şant ve 4 yaşında sağ BT şant operasyonları uygulanan, 6 yaşında yapılan kateterizasyonda pulmoner arter basınçları normal bulunan olguya bir ay önce bilateral BT şant iptali ve $20 \mathrm{~mm}$ PTFE tüp greft ile total kavapulmoner konneksiyon, ekstrakardiyak "Fontan-Kreutzer" prosedürü gerçekleştirildiği öğrenildi. Fizik bakıda; sol toraksta solunum sesleri azalmış, solunum sayısı 24/dk, kalp tepe atımı 100/dk, oksijen saturasyonu \%96 ve kan basınc1 100/60 mmHg idi. Telekardiyogramda kalp apeksinin sağda ve kardiyotorasik oranın artmış olduğu, sol akciğerin opak ve total plevral efüzyonla uyumlu görünümde olduğu izlendi (Resim 1). Toraks ultrasonografisinde solda kalınlığı 4 cm'ye ulaşan plevral efüzyon izlendi. Ekokardiyografide; ekstrakardiyak PTFE tüp greftte türbülan akım veya gradiyent saptanmadı ve vena kava süperiorda tromboz tespit edilmedi.

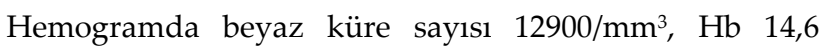
$\mathrm{gr} / \mathrm{dL}$, trombosit say1sı $385.000 / \mathrm{mm}^{3}$, eritrosit sedimentasyon hiz1 $3 \mathrm{~mm} / \mathrm{saat}$, CRP 3,2 mg/dL (0-0,5), total protein $4,8 \mathrm{gr} / \mathrm{dL}$, albumin 3,1 gr/dL, protrombin zamanı 18 sn ve İNR 1,6 saptand1. Spironolakton, aspirin ve kumadin tedavilerine devam edilerek seftriakson ve teikoplanin şeklinde ikili antibiyoterapi ve sistemik venöz basınç yükünün azaltılmasına yönelik furosemid tedavisi başlandı. Mevcut masif plevral efüzyon nedeniyle sol toraksa göğüs tüpü yerleştirilerek sualtı drenajı uygulandı ve süt görünümünde $1700 \mathrm{cc}$ mayi geldi. Plevral sıvının biyokimyasal analizinde; total kolesterol $37 \mathrm{mg} / \mathrm{dL}$, trigliserid 178 $\mathrm{mg} / \mathrm{dL}$ (total kolesterol / trigliserid $=0,20$ ), total protein 2,1 gr/dL, albumin 1,3 gr/dL, glukoz $91 \mathrm{mg} / \mathrm{dL}$, LDH $80 \mathrm{U} / \mathrm{L}$ olup sıvı kültüründe üreme saptanmazken direkt bakıda nadir lenfosit ve eritrosit saptandı. Şilotoraks tanısı konulan olguya orta zincirli yağ asitlerinden zengin ve uzun zincirli yağ asitlerinden kısıtlı diyet başlandı. Seri akciğer grafileri ile izlenen olgunun izleminin üçüncü gününde sıvı drenajında belirgin azalma olmaması üzerine olguya 2 $\mathrm{mcg} / \mathrm{kg} / \mathrm{saat}$ dozunda oktreotid infüzyonu başlandı. Oktreotid başlandığı gün sıvı drenajı $40 \mathrm{ml} / \mathrm{kg} /$ gün şeklinde olup drenaj yanıtına göre infüzyonun dozu kademeli olarak $10 \mathrm{mcg} / \mathrm{kg} / \mathrm{saat}$ 'e kadar çıkıldı. Oktreotid tedavisinin beşinci gününde sıvı drenajında belirgin azalma (3 $\mathrm{ml} / \mathrm{kg} / g u ̈ n)$ ve akciğer grafisinde plevral efüzyon miktarında belirgin gerileme saptanması üzerine doz kademeli olarak azaltıldı ve tedavinin yedinci gününde hipoglisemi semptomları gözlenmesi üzerine oktreotid tedavisi kesildi (Resim 2). Yatışının yirminci gününde göğüs tüpünden 
mayi gelmemesi üzerine göğüs tüpü çekilerek hasta taburcu edildi.

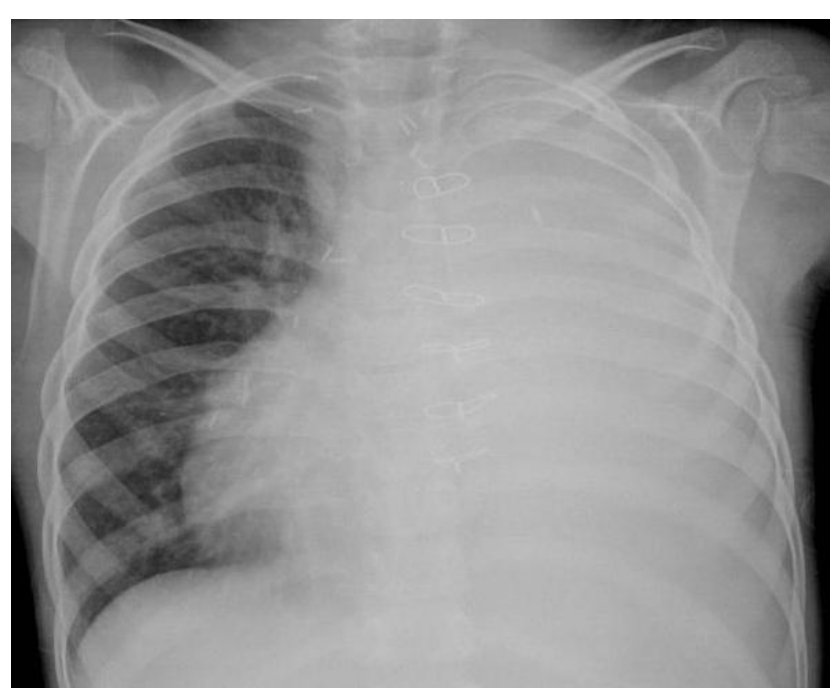

Resim 1. Oktreotid tedavisi öncesi sol akciğerde masif plevral efüzyon ile uyumlu telekardiyogram

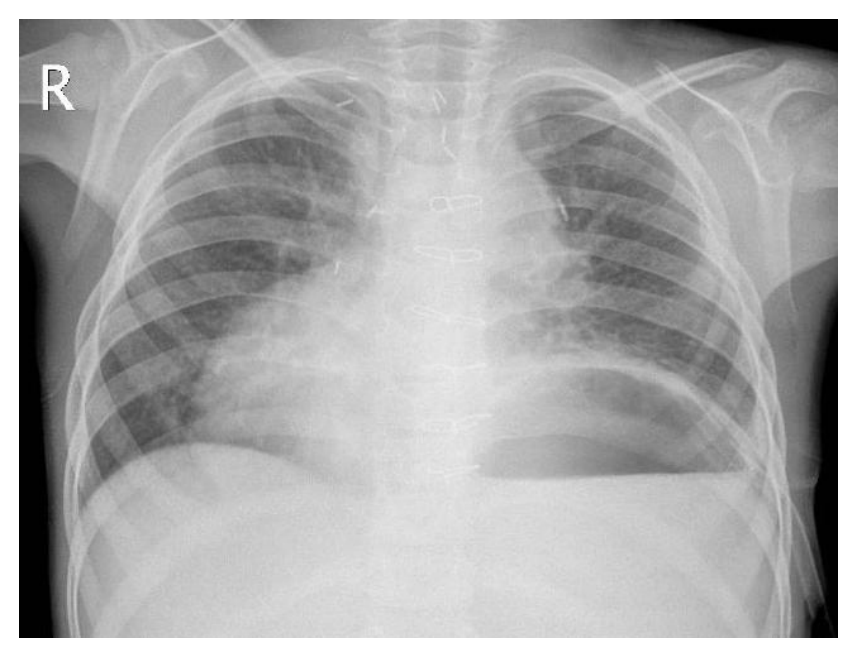

Resim 2. Telekardiyografide oktreotid tedavisinin 5 . gününde sol akciğerdeki plevral efüzyonun belirgin gerilediği izleniyor

\section{TARTIŞMA}

Edinsel şilotoraks intratorasik cerrahilerden sonra ve sıklıkla da Glenn ve Fontan prosedürleri gibi kavapul- moner anastomozlardan sonra venöz trombozlara veya artmış sistemik venöz basınca bağlı gelişebilmektedir (7). Fontan prosedürü sonrası görülen şilotoraksın süresi diğer patolojilere bağlı gelişen şilotorakstan daha uzundur (6). Bizim olgularımızda da Fontan operasyonu uygulanmış, postoperatif 1.ayda solda total şilotoraks gelişmiş ve mayi drenaj1 20. günde sona ermişti.

Şilotoraks olgularının birçoğu konservatif medikal tedaviye yanıt verir ve cerrahi girişim gerekmez (8). Geleneksel tedavinin basamakları; torasentez veya tüp torakostomi ile plevral sıvının drenajı, total parenteral beslenme, enterik istirahat ve lenfatik sistemi by-pass ederek direkt portal sisteme geçen orta zincirli yağ asitlerinden zengin diyet tedavisidir (9). Geleneksel tedaviye karşın şilöz mayi drenajına 2-3 gün içerisinde belirgin yanıt alınamıorsa intravenöz oktreotid infüzyonu başlanması önerilmektedir (10). Biz de olgumuza konservatif tedavinin 3. gününde mayi drenajının 40 $\mathrm{ml} / \mathrm{kg} /$ gün şeklinde devam etmesi üzerine $2 \mathrm{mcg} / \mathrm{kg} / \mathrm{saat}$ dozunda oktreotid infüzyonu başladık ve drenaj yanıtına göre infüzyon dozunu $10 \mathrm{mcg} / \mathrm{kg} / \mathrm{saat}$ 'e kadar arttırdık.

Postoperatif şilotoraksın tedavisinde somatostatin ilk kez 1998 yılında Rimensberger tarafından kullanılmıştır (5). Somatostatinin uzun etkili sentetik analoğu olan oktreotid, splenik ve hepatik venöz basıncı ve barsaklardan lipid emilimini azaltarak ve torasik duktusta trigliserid konsantrasyonunu düşürerek şilöz mayi üretimini azaltır (11). Oktreotidin intravenöz infüzyon dozu 0,3-10 $\mathrm{mcg} / \mathrm{kg} / \mathrm{saat}$ ve subkutan dozu $10-40 \mathrm{mcg} / \mathrm{kg} / \mathrm{gün}$ şeklindedir (5). Doz drenaj yanıtına göre titre edilmeli ve istenilen yanıt elde edildiğinde yavaş yavaş azaltılarak kesilmelidir. Birçok çalışmada etkinliğinin 5-6. günlerde başladığ 1 ve ortalama tedavi süresinin 10-18 gün arasında olduğu bildirilmektedir (12). Yan etkileri olgu bazında olup, hipoglisemi, hiperglisemi, karaciğer disfonksiyonu, hipotiroidi, batın distansiyonu, ishal, safra taşı ve nekrotizan enterokolit bildirilmiştir (11). Olgumuzda somatostatin tedavisinin beşinci gününde belirgin drenaj yanıtı alındı ve dozun yavaş yavaş azaltıldı̆̆ı yedinci günde titreme, terleme, bulanık görme gibi hipoglisemi semptomları görülmesi üzerine somatostatin tedavisi sonlandırıldı ve tedavi süresince diğer yan etkileri gözlenmedi. 
Kavapulmoner anastomoz uygulanan hasta grubunda santral venöz basınç değerleri daha yüksek olup bu durum travmatik lenfatik sistemden şilöz drenaja olumsuz katkıda bulunmaktadır (13). Fontan tipi prosedürlere bağlı şilöz mayi birikim süresi diğer etkenlerle karşılaştırıldığında anlamlı derecede uzun bulunmuştur (14). Total kavapulmoner konneksiyon yapılan 108 hastanın uzun dönem izleminde sadece bir hastada şilotoraks görülmüş hatta Fontan operasyonu sonrası izlemde gelişen şiloptizi nedeniyle kalp transplantasyonu uygulanan bir vaka bildirilmiştir $(15,16)$. Olgumuzda şilöz drenaj postop 1 . ayda görüldü ve tedavinin 20. gününde tamamen kesildi.

Konservatif tedavinin 3-4. haftasında mayi drenaj1 10 $\mathrm{ml} / \mathrm{kg} /$ gün şeklinde halen devam eden vakalarda cerrahi girişim seçenekleri düşünülebilir (17). Bunlar; torasik duktus ligasyonu, plörodezis veya plöro-peritoneal şant ameliyatlarıdır (18). Yakın zamanda cerrahiye alternatif daha az invazif olan prosedürler video-assisted torakoskopi eşliğinde torasik duktus ligasyonu ve perkütan torasik duktus embolizasyonu da çocuklarda başarı ile uygulanmıştır $(19,20)$. Hastamızda yatışının 3.haftasında medikal tedaviye tam yanıt alınmış olup cerrahi tedavi seçeneği gündeme gelmemiştir.

Sonuç olarak; açık kalp cerrahisi geçiren çocuklarda ve özellikle kavapulmoner anastomoz uygulanan hastalarda postop dönemde görülebilen plevral efüzyonda şilotoraks akla getirilmeli ve konservatif tedaviye yeterince yanıt vermeyen olgularda oktreotid ile etkin ve güvenli bir şekilde plevral mayi kontrolünün sağlanması, cerrahi seçenekler öncesi değerlendirilmesi gereken uygun bir tedavi yaklaşımıdır.

\section{KAYNAKLAR}

1. Panthongviriyakul C, Bines JE. Postoperative chylothorax in children: an evidence-based management algorithm. J Paediatr Child Health 2008;44:716-721.

2. Tavli V, Yılmazer MM, Güven B, Mese B, Lafci B, Gürbüz A. Octreotide treatment for chylothorax after congenital heart surgery. J Card Surg 2009;24:570-571.

3. Lim KA, Kim SH, Huh J, et al. Somatostatin for postoperative chylothorax after surgery for children with congenital heart disease. J Korean Med Sci 2005;20:947-951.

4. Sersar SI. Predictors of prolonged drainage of chylotho- rax after cardiac surgery: single centre study. Pediatr Surg Int 2011;27:811-815.

5. Zuluaga MT. Chylothorax after surgery for congenital heart disease. Cur Opin Pediatr 2012;24:291-294.

6. Parames F, Freitas I, Fragata J, Trigo C, Pinto MF. Octreotide-additional conservative therapy for postoperative chylothorax in congenital heart disease. Rev Port Cardiol 2009;28:799-807.

7. Bond SJ, Guzzetta PC, Snyder ML, Randolph JG. Management of pediatric postoperative chylothorax. Ann Thorac Surg 1993;56:469-472.

8. Biewer ES, Zürn C, Arnold R, et al. Chylothorax after surgery on congenital heart disease in newborns and infants - risk factors and efficacy of MCT-diet. J Cardiothorac Surg 2010;13:127.

9. Chan EH, Russell JL, Williams WG, Van Arsdell GS, Coles JG, McCrindle BW. Postoperative chylothorax after cardiothoracic surgery in children. Ann Thorac Surg 2005;80:1864-1870.

10. Roehr CC, Jung A, Proquitté H, et al. Somatostatin or octreotide as treatment options for chylothorax in young children: a systematic review. Intensive Care Med 2006;32:650-657.

11. Grosman I, Simon D. Potential gastrointestinal uses of somatostatin and its synthetic analogue octreotide. Am J Gastroenterol 1990; 85:1061-1072.

12. Caverly L, Rausch CM, da Cruz E, Kaufman J. Octreotide treatment of chylothorax in pediatric patients following cardiothoracic surgery. Congenit Heart Dis 2010;5:573-578.

13. Landvoigt MT, Mullett CJ. Octreotide efficacy in the treatment of chylothoraces following cardiac surgery in infants and children. Pediatr Crit Care Med 2006;7:245248.

14. Chan SY, Lau W, Wong WH, Cheng LC, Chau AK, Cheung YF. Chylothorax in children after congenital heart surgery. Ann Thorac Surg 2006;82:1650-1656.

15. Yoshimura N, Yamaguchi M, Oka S, et al. Long-term results after the total cavopulmonary connection. Kyobu Geka 2003;56:289-293.

16. Robotin MC, Edis BD, Weintraub RG, Pawade A, Karl TR. Heart transplantation for chyloptysis after Fontan operation. Ann Thorac Surg 1995;59:1570-1571. 
17. Cannizzaro V, Frey B, Bernet-Buettiker V. The role of somatostatin in the treatment of persistent chylothorax in children. Eur J Cardiothorac Surg 2006;30:49-53.

18. Nath DS, Savla J, Khemani RG, Nussbaum DP, Greene CL, Wells WJ. Thoracic duct ligation for persistent chylothorax after pediatric cardiothoracic surgery. Ann Thorac Surg 2009;88:246-251.

19. Pego-Fernandes PM, Nascimbem MB, Ranzani OT,
Shimoda MS, Monteiro R, Jatene FB. Video-assisted thoracoscopy as an option in the surgical treatment of chylothorax after cardiac surgery in children. J Bras Pneumol 2011;37:28-35.

20. Itkin M, Krishnamurthy G, Naim MY, Bird GL, Keller MS. Percutaneous thoracic duct embolization as a treatment for intrathoracic chyle leaks in infants. Pediatrics 2011; 128:237-241. 